\title{
The influence of tennis court surfaces on player perceptions and biomechanical response
}

\section{Chelsea Starbuck, Loïc Damm, James Clarke, Matt Carré, Jamie Capel-Davis, Stuart Miller, Victoria Stiles \& Sharon Dixon}

To cite this article: Chelsea Starbuck, Loïc Damm, James Clarke, Matt Carré, Jamie CapelDavis, Stuart Miller, Victoria Stiles \& Sharon Dixon (2015): The influence of tennis court surfaces on player perceptions and biomechanical response, Journal of Sports Sciences, DOI: 10.1080/02640414.2015.1127988

To link to this article: $\mathrm{http}: / / d x . d o i . o r g / 10.1080 / 02640414.2015 .1127988$

Submit your article to this journal $₫$

View related articles \lceil

View Crossmark data $₫$ 


\title{
The influence of tennis court surfaces on player perceptions and biomechanical response
}

\author{
Chelsea Starbuck ${ }^{a, b}$, Loïc Damm ${ }^{b}$, James Clarke ${ }^{c}$, Matt Carréc, Jamie Capel-Davis ${ }^{d}$, Stuart Miller ${ }^{d}$, Victoria Stiles ${ }^{a}$ \\ and Sharon Dixon ${ }^{a}$
}

\begin{abstract}
aSport and Health Sciences, University of St Mark and St John, Plymouth, UK; ${ }^{\text {b} E x e t e r ~ B i o m e c h a n i c s ~ T e a m, ~ S p o r t ~ a n d ~ H e a l t h ~ S c i e n c e s, ~ U n i v e r s i t y ~ o f ~}$ Exeter, St Lukes Campus, Exeter, UK; 'Department of Mechanical Engineering, Sports Engineering Research Group, University of Sheffield, Sheffield, UK; dInternational Tennis Federation, London, UK
\end{abstract}

\begin{abstract}
This study aimed to examine player perceptions and biomechanical responses to tennis surfaces and to evaluate the influence of prior clay court experience. Two groups with different clay experiences (experience group, $n=5$ and low-experience group, $n=5$ ) performed a $180^{\circ}$ turning movement. Three-dimensional ankle and knee movements $(50 \mathrm{~Hz})$, plantar pressure of the turning step $(100 \mathrm{~Hz})$ and perception data (visual analogue scale questionnaire) were collected for two tennis courts (acrylic and clay). Greater initial knee flexion (acrylic 20. $8 \pm 11.2^{\circ}$ and clay $32.5 \pm 9.4^{\circ}$ ) and a more upright position were reported on the clay compared to the acrylic court $(P<0.05)$. This suggests adaptations to increase player stability on clay. Greater hallux pressures and lower midfoot pressures were observed on the clay court, allowing for sliding whilst providing grip at the forefoot. Players with prior clay court experience exhibited later peak knee flexion compared to those with low experience. All participants perceived the differences in surface properties between courts and thus responded appropriately to these differences. The level of previous clay court experience did not influence players' perceptions of the surfaces; however, those with greater clay court experience may reduce injury risk as a result of reduced loading through later peak knee flexion.
\end{abstract}

ARTICLE HISTORY

Accepted 28 November 2015

\section{KEYWORDS}

Playing experience; turning; pressure; kinematics

\section{Introduction}

Tennis surfaces, such as clay and acrylic courts, can differ greatly in mechanical properties such as friction and hardness. These differences have been associated with changes in performance as a result of altered movement patterns and styles of play (O'Donoghue \& Ingram, 2001; Reid et al., 2013). Compared with low-friction surfaces, high-friction surfaces lead to kinematic adjustments (Dowling, Corazza, Chaudhari, \& Andriacchi, 2010; Farley, Glasheen, \& McMahon, 1993), such as lower attack angles (measured to the horizontal), in addition to faster running speeds and movements (Brechue, Mayhew, \& Piper, 2005). Players have been observed to accommodate to low-friction surfaces such as clay through sliding (Miller, 2006).

Lower injury rates have been reported on clay courts compared to acrylic hardcourts, suggested to be a result of lower friction (Bastholt, 2000; Nigg \& Segesser, 1988). Higher friction surfaces, such as acrylic hardcourts, have been associated with high loading, particularly on the lateral regions of the foot (Damm et al., 2014). This suggests the foot to be in an inverted position. High levels of inversion $\left(16^{\circ}\right)$ have previously been linked to ankle inversion injuries (Kristianslund, Bahr, \& Krosshaug, 2011). When examining $180^{\circ}$ turning movement on a range of test surfaces (including wood, asphalt and synthetic rubber), kinematic adjustments to the high-friction surfaces included longer braking phases and greater knee flexion
(Durá, Hoyos, Martínez, \& Lozano, 1999). These adjustments have been suggested to contribute to the occurrence of patellofemoral pain (Chard \& Lachmann, 1987; Damm et al., 2013; Gecha \& Torg, 1988), a commonly reported injury in tennis (Abrams, Renstrom, \& Safran, 2012). Alternatively, cutting tasks on high-friction surfaces have been reported to produce lower knee flexion angles resulting in an increased risk of anterior cruciate ligament $(A C L)$ injuries (Dowling et al., 2010).

Pressure insoles provide a tool to examine loading during on-court scenarios. The distribution and the magnitude of force within foot regions have been suggested as good indicators of injury risks compared to overall force magnitude (Damm et al., 2014; Girard, Eicher, Fourchet, Micallef, \& Millet, 2007; Stiles \& Dixon, 2007; Willems et al., 2005). In tennis, lower whole foot loads have been reported for clay courts compared with acrylic suggesting lower risk of injury on the clay (Damm et al., 2012; Girard et al., 2007). Court surface types have also been associated with different pressure distribution patterns (Damm et al., 2012, 2014; Girard, Micallef, \& Millet, 2010; Girard et al., 2007). Girard et al. (2007) reported greater midfoot and hallux pressures on an acrylic court compared to a clay court during tennis-specific movements and associated these greater pressures with greater injury risk on the acrylic court.

Mechanical tests measure surface properties, yet due to players' ability to adapt to different properties through 
biomechanical adjustments, mechanical tests are unable to replicate players experiences of tennis surfaces (Damm et al., 2013; Dixon, Collop, \& Batt, 2000; Ferris, Liang, \& Farley, 1999). Perceptions have been suggested to be an important link between mechanical properties and player biomechanics (Fleming, Young, Roberts, Jones, \& Dixon, 2005). Perceptions can provide information on humans' ability to identify and respond to their environment (Milani, Hennig, \& Lafortune, 1997; Stiles \& Dixon, 2007). Previous experience and sensory information are combined to formulate perceptions and enable humans to interact successfully within their environment (Coren, Porac, \& Ward, 1979; Sherwood, 1993). Studies of sports surfaces have mainly focused on perceptions of hardness and grip, whilst Fleming et al. (2005) identified other perceptions such as surface abrasiveness to be important, following interviews with 22 hockey players. Therefore, further research is required to examine additional perception parameters of court surfaces to provide better understanding of how tennis surface properties alter player movement and loading. Greater understanding of tennis players' perceptions and biomechanical response could also enable the development of mechanical tests to better characterise court surface properties.

In addition to influencing perceptions, previous experience can alter human response to surface conditions (Chiou, Bhattacharya, \& Succop, 2000; Coren et al., 1979; Heiden, Sanderson, Inglis, \& Siegmund, 2006). It has previously been observed that prior experience and awareness of slippery surfaces results in the adoption of a cautious gait (greater initial knee flexion), leading to reduced ground reaction force (GRF) and increased muscle activity during walking (Heiden et al., 2006). Heiden et al. (2006) examined walking, whilst there has been no research examining the influence of previous experience of surface conditions during sport-specific movements such as turning.

This study aims to examine the influence of changes in tennis surface upon perceptions and biomechanical variables to better understand the influence of perceptions upon factors associated with increased injury risk and to enable future development of mechanical tests. Based on literature evidence, it was anticipated that tennis court properties would influence tennis players' perceptions and biomechanical response. Specifically, it was hypothesised that players would perceive greater hardness on the acrylic court as a result of greater peak heel pressures. Lower perceptions of grip on the clay court would be observed alongside greater initial knee flexion associated with reduced $A C L$ injury risk. The study also aimed to evaluate the influence of previous experience of clay courts upon perceptions and biomechanics. It was hypothesised that those with prior experience of clay courts would adapt to increase stability through reduced GRF and further increases in knee flexion.

\section{Methods}

\subsection{Participant information}

Ten tennis players (Lawn Tennis Association (LTA) rating $3.6 \pm 1.3$ ) volunteered to participate in the current study. Players were grouped into two groups according to their experience with playing on clay courts. These groupings were determined by questionnaire where those who rated their experience on clay as high or above (defined as once a month or more) were selected for the experienced group $(n=5$, LTA rating $3.0 \pm 1.6$, age $28.0 \pm 5.1$ years, height $1.8 \pm 0.1 \mathrm{~m}$ and weight $75.0 \pm 14.3 \mathrm{~kg}$ ), whereas those who rated no to moderate experience (once a year or less) formed the low-experience group ( $n=5$, LTA rating $3.8 \pm 1.1$, age $26.0 \pm 1.3$ years, height $1.7 \pm 0.1 \mathrm{~m}$ and $65.8 \pm 12.8 \mathrm{~kg}$ ). No statistical differences (using independent $t$-tests) in LTA ratings and anthropometric data were observed between groups. The study was approved by the Institutional Ethics Committee and informed consent was obtained before testing.

Participants were required to perform $10 \times 180^{\circ}$ turns on two tennis courts (GreenSet Grand Prix Acrylic laid directly on asphalt and Northern European Clay, order randomly assigned) at the National Tennis Centre (NTC), London. Participants ran $5.5 \mathrm{~m}$ along the baseline through timing gates placed $3 \mathrm{~m}$ apart at a speed of $3.9 \pm 0.20 \mathrm{~m} \cdot \mathrm{s}^{-1}$ before performing the turn. Participants wore the same shoes on both tennis courts (adidas Barricade 6.0 clay court shoes with a v-shaped tread pattern) and were given adequate time to habituate themselves with the court and movement before testing.

\subsection{Mechanical data}

Mechanical tests were conducted to provide details of surface properties for each tennis court. A pendulum test (Slip resistance test, ITF CS 02/01) was conducted to provide a measure of dynamic translational friction of the court surfaces (Miller \& Capel-Davies, 2006). The test has previously been used to examine surface friction on clay and acrylic tennis courts (Damm et al., 2013, 2014; Miller \& Capel-Davies, 2006). The pendulum test was conducted on five different locations on the baseline of the court. Eight repeats were conducted at each location with the first three repeats being disregarded. Therefore, five valid repeats were collected in five locations along the baseline of each court. The Crab III device (developed by the ITF; (Miller \& Capel-Davies, 2006) was used to obtain a measure of static translational friction. Data were collected from ten separate locations around the baseline area of each tennis court. Making consistent measurements on the clay court proved challenging with both friction test devices as the surface particles were disturbed between trials, therefore reducing the validity of the test devices.

Mechanical hardness and stiffness were measured using the Sports Engineering Research Group (SERG) impact hammer, first described by Carre, James, and Haake (2006). To simulate actual conditions and to prevent damage to the tennis courts, an outsole of a tennis shoe was attached onto the rigid steel hammer, which has previously been successful in comparing impact characteristics of tennis surfaces (Yang, 2010). Peak force was measured during impact with the surface to indicate differences in surface hardness. Average stiffness was reported as the ratio of the peak force and the related displacement. The SERG impact hammer test was conducted on ten separate locations in the baseline area of the court. 
COMPLETELY UNPREDICTABLE

Unstable, uneven, Messy, unexpected

NO GRIP

Slippery \& loose

SOFTEST SURFACE

Padded, cushioned, compliant

\section{VERY EASY TO PUSH OFF/ \\ CHANGE DIRECTION}

No difficulties, no problems

VERY EASY TO SLIDE

No difficulties, no problems

\section{COMPLETELY PREDICTABLE}

Stable, even, secure, expected

\section{TOO MUCH GRIP}

Secure \& grippy

\section{HARDEST SURFACE}

High energy, impacts

hard, stiff

\section{VERY HARD TO PUSH OFF/ CHANGE DIRECTION \\ Very difficult, impossible}

\section{VERY HARD TO SLIDE}

Very difficult, impossible

Figure 1. The perception scales including the descriptive end phrases.

\subsection{Perception data}

A short questionnaire comprising of five visual analogue scales (VAS; Figure 1) was used to collect perception data following play on each court (Starbuck, 2015). These scales were $100 \mathrm{~mm}$ in length with two descriptive end phrases, formulated from parameters and language identified in previous qualitative pilot work. Perception parameters included perceived predictability, grip, hardness, ability to change direction and ability to slide.

\subsection{Kinematic data}

Kinematic data were collected using three video cameras (Sony HDV 1080i mini DV). The video data were then deinterlaced to provide a sampling frequency of $50 \mathrm{~Hz}$ with images of 720 pixel. Event synchronisation of LED lights were used to synchronise the cameras with a maximum error of $0.02 \mathrm{~s}$. Direct linear transformations (DLT) using Vicon Motus (v9.2) software reconstructed three-dimensional coordinates from the two-dimensional digitised coordinates of each camera (Abel-Aziz \& Karara, 1971). Reconstruction errors, calculated using root mean square error (RMSE) of four known markers, were no larger than $0.01 \mathrm{~m}$ in the $x, y$ and $z$ direction. Eleven markers (Figure 2) were placed upon the lower limb of the dominant leg, enabling increased accuracy and reliability of manual digitisation as well as defining the joint coordinate systems adapted from (Grood \& Suntay, 1983; Soutas-Little, Beavis, Verstraete, \& Markus, 1987). The three-dimensional lower limb coordinates were filtered using a recursive 2nd order Butterworth filter, with an optimum cut off frequency (range of 4-8 Hz) for each coordinate determined using residual analysis.

Rotations about the ankle and knee joint centres were determined using a custom written Matlab code (Matlab, R2011b, MathWorks, Natrick, MA, USA). All kinematic data were presented relative to a relaxed standing trial. Kinematic variables included initial and peak inversion angles, initial ankle flexion and peak dorsiflexion angles

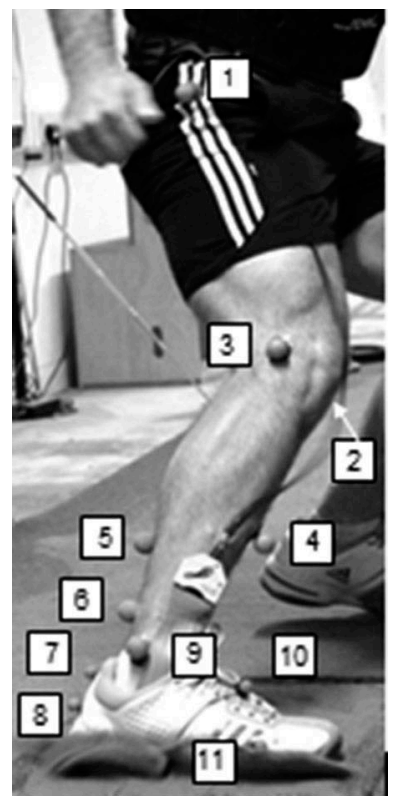

Figure 2. Joint coordinate system marker locations: (1) hip (greater trochanter), (2) medial knee (medial femoral epicondyle), (3) lateral knee (lateral femoral epicondyle), (4) shin (anterior aspect of shank), (5) Achilles 1 (proximal bisection of posterior shank), (6) Achilles 2 (distal bisection of the posterior shank), (7) calcaneus 1 (proximal bisection of the calcaneus), (8) calcaneus 2 (distal bisection of the calcaneus), (9) lateral malleolus, (10) toe (base of 2nd metatarsal) and (11) 5th metatarsal phalange.

and initial and peak knee flexion angles. Occurrence times of peak angles were reported relative to heel contact. Sliding distance was calculated from the resultant distance covered by the 5th metatarsal during ground contact. Attack angle at impact was defined as the angle between the $x y$ plane and the calcaneus to hip vector. Estimated errors for all angles were less than $1^{\circ}$.

\subsection{Pressure data}

Pressure insoles (Pedar, Novel, $\mathrm{GmbH}$, Munich) were used to obtain pressure data at $100 \mathrm{~Hz}$ for the turning step. Eight 


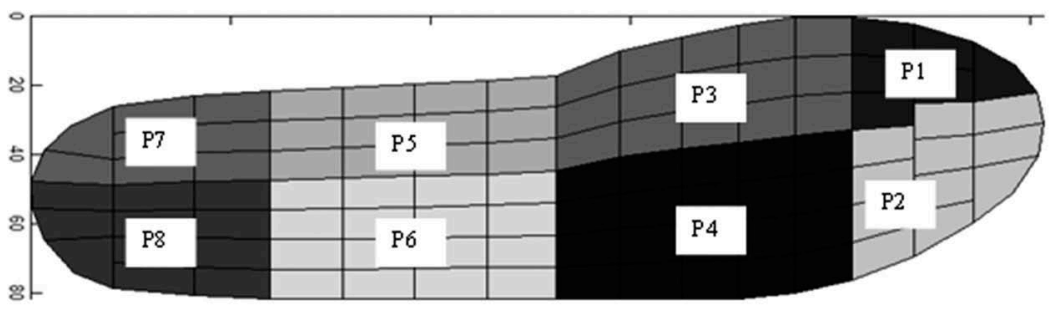

Figure 3. A representation of the eight masks (right foot) used; P1: hallux, P2: lesser toes, P3: medial forefoot, P4: lateral forefoot, P5: medial midfoot, P6: lateral midfoot, P7: medial heel and P8: lateral heel.

masks, as previously used by Damm et al. (2012), allowed for a detailed analysis of plantar foot sections (Figure 3), which included the lateral and medial heel, midfoot and forefoot and the hallux and lesser toes. Variables for both whole foot and foot regions included mean and maximum pressures, peak impact and active forces, peak and average loading rates, and impulse. Occurrence times of peak impact and active forces and maximum pressures were also identified. To ensure an accurate assessment, a drift correction, recommended by Hurkmans, Bussmann, Benda, Verhaar, and Stam (2006), was implemented for the pressure data.

\subsection{Statistical analysis}

Comparisons between the clay experience groups and the surfaces were examined for kinematic and perception data using a two-way analysis of variance (ANOVA) with repeated measures, with Bonferonni's corrected alpha post hoc analysis. Standardised effect sizes (ES) were calculated using partial Eta ${ }^{2}$ to provide the degree to which the differences were present (Cohen, 1977). ES were presented for either differences between groups and within groups (court differences) when significance was observed for these effects. Some trials from the pressure data were omitted due to a failed wireless transmission, resulting in data for only four participants in the low-experience group and three participants in the experienced group, meaning group comparisons could not be made for pressure variables. Therefore, a paired $t$-test was conducted to examine differences for the whole cohort of players between the two courts. Statistical analysis was conducted using SPSS (v.19) software. An alpha level of less than 0.05 determined significance.

\section{Results}

\subsection{Mechanical data}

The clay court had lower static and dynamic coefficients of friction compared to the acrylic court (Table 1). Peak force measured by the SERG impact hammer was greater on the acrylic court compared to the clay court, indicating greater hardness of the acrylic court (Clarke, Carré, Damm, \& Dixon, 2013). Stiffness was also measured by the SERG impact hammer and was greater on the acrylic court compared to the clay court $(P<0.05)$.
Table 1. Means and standard deviations for mechanical data collected on the acrylic and clay court.

\begin{tabular}{lcc}
\hline Mechanical test & Acrylic & Clay \\
\hline Frictional measures & & \\
Pendulum (COF) & $0.710 \pm 0.027$ & $0.578 \pm 0.034^{*}$ \\
Crab III (COF) & $1.29 \pm 0.05$ & $0.85 \pm 0.15^{*}$ \\
Hardness measures & & \\
SERG impact hammer & & \\
Peak force (N) & $1751.55 \pm 5.87$ & $1723.9 \pm 22.15^{*}$ \\
Stiffness $\left(\mathrm{kN} \cdot \mathrm{m}^{-1}\right)$ & $302.75 \pm 20.44$ & $279.46 \pm 12.96^{*}$ \\
\hline
\end{tabular}

*Denotes a $(P<0.05)$ difference between tennis courts.

\subsection{Tennis court differences}

The analysis revealed differences between tennis courts for all perception parameters (Figure 4). The acrylic court was rated to be more predictable, have more grip, greater hardness and was harder to slide on when compared with the clay court. However, the clay court was perceived to be harder to change direction compared to the acrylic court.

Sliding distances were greater $(\mathrm{ES}=0.598, P<0.05)$ on the clay court $(0.66 \pm 0.40 \mathrm{~m})$ compared to the acrylic court $(0.35 \pm 0.04 \mathrm{~m})$. Ground contact time $(\mathrm{ES}=0.838, P<0.05)$ was longer on the clay court $(0.54 \pm 0.11 \mathrm{~s})$ compared to the acrylic court $(0.35 \pm 0.04 \mathrm{~s})$. Represented schematically (Figure 5), initial attack angle was higher on the clay court $\left(74.4 \pm 6.1^{\circ}\right)$ compared to the acrylic court $\left(64.8 \pm 5.3^{\circ}\right.$, $\mathrm{ES}=0.572, P<0.05)$. Greater initial knee flexion angle, indicating greater flexion, was observed on the clay court $\left(32.5 \pm 9.4^{\circ}\right.$; Table 2$)$ compared to the acrylic court $\left(20.8 \pm 11.2^{\circ}, P<0.05\right)$. No court differences occurred for peak ankle dorsiflexion angle. However, later peak dorsiflexion ( $E S=0.694, P<0.05$ ) occurred on the clay court $(0.28 \pm 0.10 \mathrm{~s})$ compared to the acrylic court $(0.16 \pm 0.10 \mathrm{~s})$.

The acrylic court produced $(P<0.05)$ greater peak impact forces, peak active forces, average loading rates, peak loading rates and impulse compared to the clay court (Table 3 ). Peak active force occurred earlier on the acrylic compared to the clay court. No differences between the tennis courts were identified for whole foot mean and maximum pressures.

Greater maximum pressure in the hallux region $(E S=1.73$, $P<0.05$; Figure 6) occurred on the clay $(36.40 \pm 9.64 \mathrm{kPa})$ compared to the acrylic court $(24.14 \pm 12.13 \mathrm{kPa})$. Differences between the courts were detected for the maximum pressures at the lateral ( $E S=1.06, P<0.05$ ) and medial heel regions (ES $=1.49, P<0.05)$. Lower maximum heel pressures were produced on the clay court (lateral $=18.36 \pm 4.77 \mathrm{kPa}$ and 


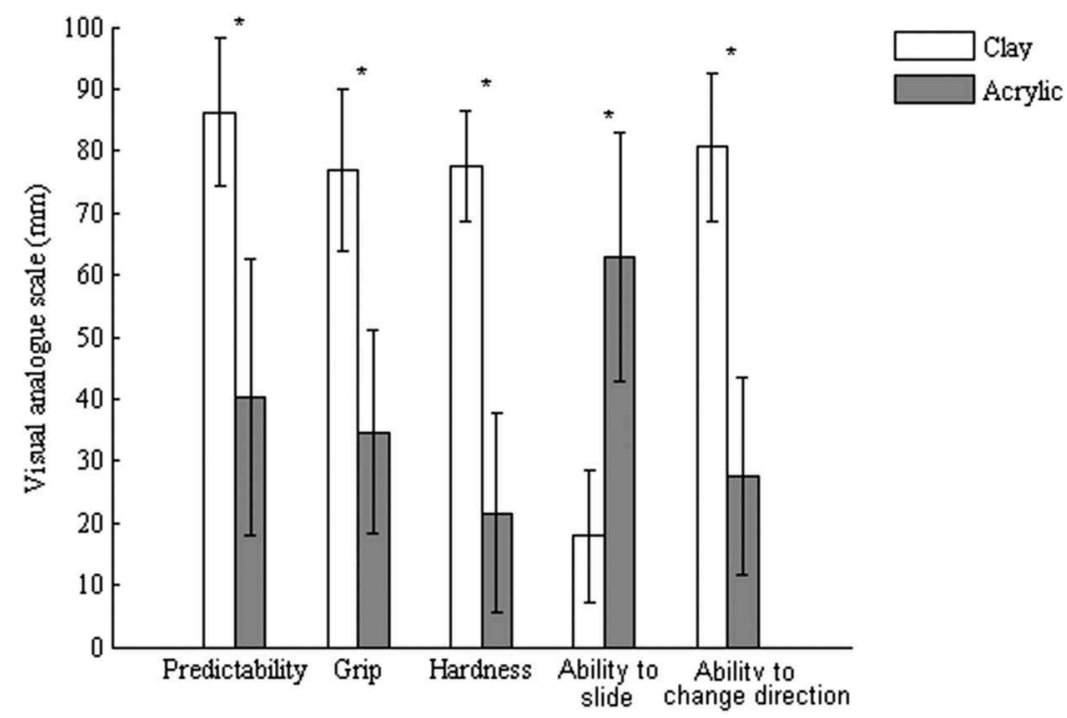

Figure 4. Means and SD for the perception parameters and comparison between the clay court and hard court. *Denotes a $(P<0.05)$ difference between courts.

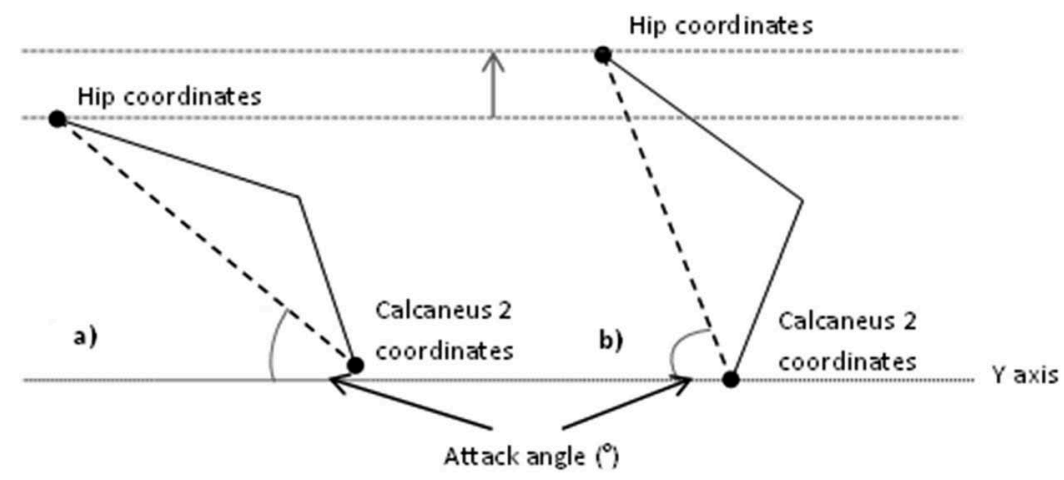

Figure 5. A schematic diagram representing attack angle, where attack angle is defined as the angle between the horizontal axis and calcaneus to hip vector. (a) Represents a greater attack angle reported for the acrylic court and (b) presents a more upright position observed on the clay court, with a greater hip height compared to the acrylic court.

Table 2. Means and standard deviations for kinematic data during the turning movement on each tennis court for both experience groups.

\begin{tabular}{|c|c|c|c|c|c|c|c|}
\hline \multirow[b]{2}{*}{ Variable } & \multicolumn{3}{|c|}{ Acrylic court } & \multicolumn{3}{|c|}{ Clay court } & \multirow[b]{2}{*}{ ES } \\
\hline & Experience group & Low-experience group & Total & Experience group & Low-experience group & Total & \\
\hline \multicolumn{8}{|l|}{ Ankle dorsiflexion } \\
\hline At impact $\left({ }^{\circ}\right)$ & $-2.5 \pm 7.7$ & $3.3 \pm 8.3$ & $0.4 \pm 8.1$ & $7.7 \pm 9.4$ & $3.3 \pm 8.3$ & $2.5 \pm 10.2$ & $0.562^{i}$ \\
\hline Time of peak (s) & $0.11 \pm 0.09$ & $0.20 \pm 0.054$ & $0.16 \pm .1$ & $0.29 \pm 0.13$ & $0.27 \pm 0.09$ & $0.28 \pm 0.10$ & $0.694^{*}$ \\
\hline \multicolumn{8}{|l|}{ Ankle inversion } \\
\hline At impact $\left(^{\circ}\right)$ & $-0.3 \pm 6.6$ & $-1.7 \pm 7.0$ & $-1.0 \pm 6.5$ & $3.5 \pm 6.7$ & $-4.9 \pm 6.1$ & $-0.7 \pm 7.5$ & \\
\hline Peak $\left(^{\circ}\right)$ & $-14.3 \pm 10.1$ & $-10.3 \pm 4.1$ & $-12.3 \pm 7.6$ & $-8.6 \pm 4.4$ & $-11.4 \pm 3.3$ & $-10.0 \pm 4.0$ & \\
\hline At impact $\left(^{\circ}\right)$ & $17.3 \pm 9.5$ & $24.3 \pm 12.7$ & $20.8 \pm 11.2$ & $28.1 \pm 9.1$ & $37.0 \pm 8.2$ & $32.5 \pm 9.4$ & $0.476^{*}$ \\
\hline Peak $\left(^{\circ}\right)$ & $31.2 \pm 18.2$ & $49.6 \pm 9.7$ & $40.4 \pm 16.8$ & $51.2 \pm 17.6$ & $42.7 \pm 23.7$ & $47.0 \pm 20.2$ & \\
\hline Time of peak (s) & $0.16 \pm 0.12$ & $0.12 \pm 0.10$ & $0.14 \pm 0.10$ & $0.36 \pm 0.11$ & $0.15 \pm 0.12$ & $0.26 \pm 0.16$ & $0.456^{9}$ \\
\hline
\end{tabular}

*Denotes a $(P<0.05)$ difference between courts, $i$ represents an $(P<0.05)$ interaction between court and group, g represents a $(P<0.05)$ difference between groups.

medial $=16.39 \pm 4.77 \mathrm{kPa}$ ) compared to the acrylic court (lateral $=26.57 \pm 7.45 \mathrm{kPa}$ and medial $=24.68 \pm 6.88 \mathrm{kPa}$ ). Lower mean (Figure 7) lateral midfoot pressures $(E S=0.334$, $P<0.05)$ were revealed on the clay court $(3.83 \pm 4.41 \mathrm{kPa})$ compared to the acrylic court $(4.98 \pm 4.92 \mathrm{kPa})$.

\subsection{The influence of previous clay court experience on} perceptions and biomechanical response

All perception parameters except players' perceived ability to change direction were similar between experience groups. The experience group perceived it easier (33.7\%) to change 
Table 3. Means and standard deviations for whole foot pressure data during the turn for each tennis court.

\begin{tabular}{lccc}
\hline Variable & Acrylic court & Clay court & ES \\
\hline Impact force & & & \\
$\quad$ Peak (BW) & $2.86 \pm 0.78$ & $2.14 \pm 0.59$ & $1.688^{*}$ \\
$\quad$ Time of peak $(\mathrm{s})$ & $0.13 \pm 0.06$ & $0.12 \pm 0.03$ & \\
Active force & & & \\
$\quad$ Peak (BW) & $2.92 \pm 0.75$ & $2.37 \pm 0.46$ & $1.055^{*}$ \\
$\quad$ Time of peak $(\mathrm{s})$ & $0.17 \pm 0.09$ & $0.29 \pm 0.12$ & $0.985^{*}$ \\
Loading rate & & & \\
$\quad$ Average $\left(\mathrm{BW} \cdot \mathrm{s}^{-1}\right)$ & $32.69 \pm 11.44$ & $21.43 \pm 6.20$ & $1.110^{*}$ \\
$\quad$ Peak (BW $\left.\cdot \mathrm{s}^{-1}\right)$ & $83.62 \pm 12.74$ & $65.48 \pm 28.50$ & $0.767^{*}$ \\
$\quad$ Impulse (BW $\left.\cdot \mathrm{s}^{-1}\right)$ & $11.47 \pm 3.80$ & $8.11 \pm 2.00$ & $1.22^{*}$ \\
Whole foot pressure & & & \\
$\quad$ Maximum pressure $(\mathrm{kPa})$ & $49.31 \pm 10.56$ & $49.5 \pm 10.74$ & \\
$\quad$ Mean pressure $(\mathrm{kPa})$ & $14.29 \pm 18.49$ & $13.23 \pm 17.29$ & \\
\hline
\end{tabular}

*Denotes a $(P<0.05)$ difference between the clay and the acrylic court.

direction compared to the low-experience group $(P<0.05)$ irrespective of tennis court. The experience group $(0.26 \pm 0.03 \mathrm{~s})$ produced later peak knee flexion $(E S=0.456$,
$P<0.05)$ compared to the low-experience group $(0.14 \pm 0.03 \mathrm{~s})$. An interaction between group and court was revealed ( $E S=0.562 P<0.05$ ) for initial ankle flexion angle. Post hoc analysis indicated differences between tennis courts for the experienced group but no differences for the lowexperience group. At impact, the experienced group was plantar flexed on clay $\left(7.7 \pm 9.4^{\circ}\right)$, whilst this group was neutral or slightly dorsiflexed on the acrylic court $\left(-2.5 \pm 7.5^{\circ}\right)$.

\section{Discussion}

The main purpose of this study was to examine tennis players' perceptions and biomechanical response on two tennis court surfaces with distinct cushioning and friction properties - an acrylic court and a clay court. A second aim was to investigate the influence of previous clay court experience on player perceptions and response. Court differences in player perceptions and response were observed, whilst group differences

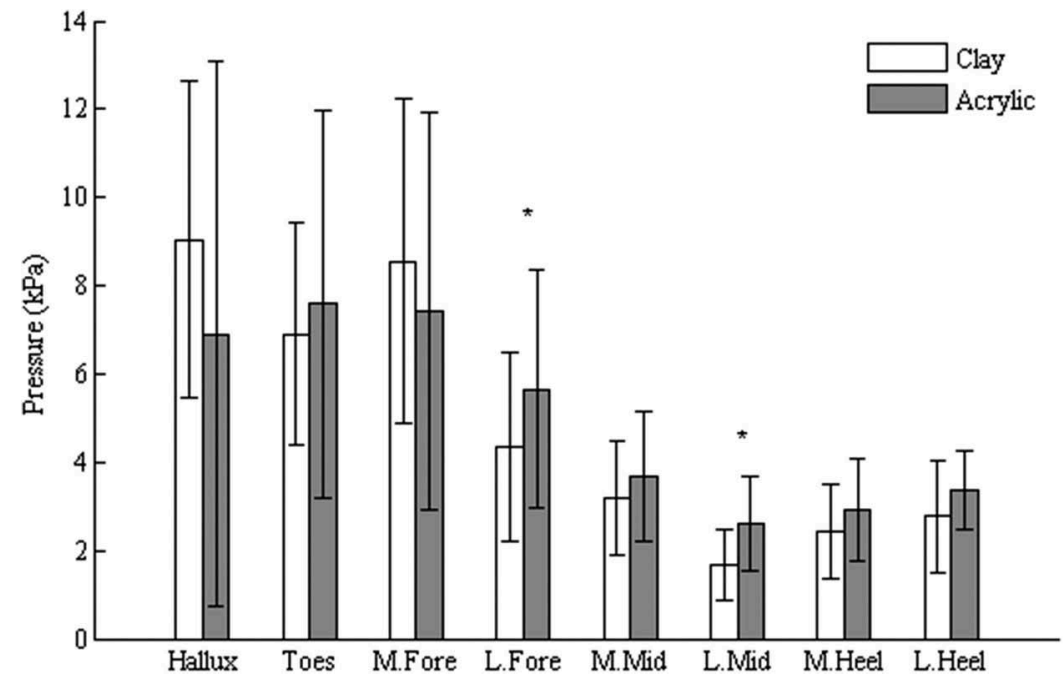

Figure 6. Maximum pressures for the eight masks on acrylic and clay court.

*Denotes a $(P<0.05)$ difference between courts.

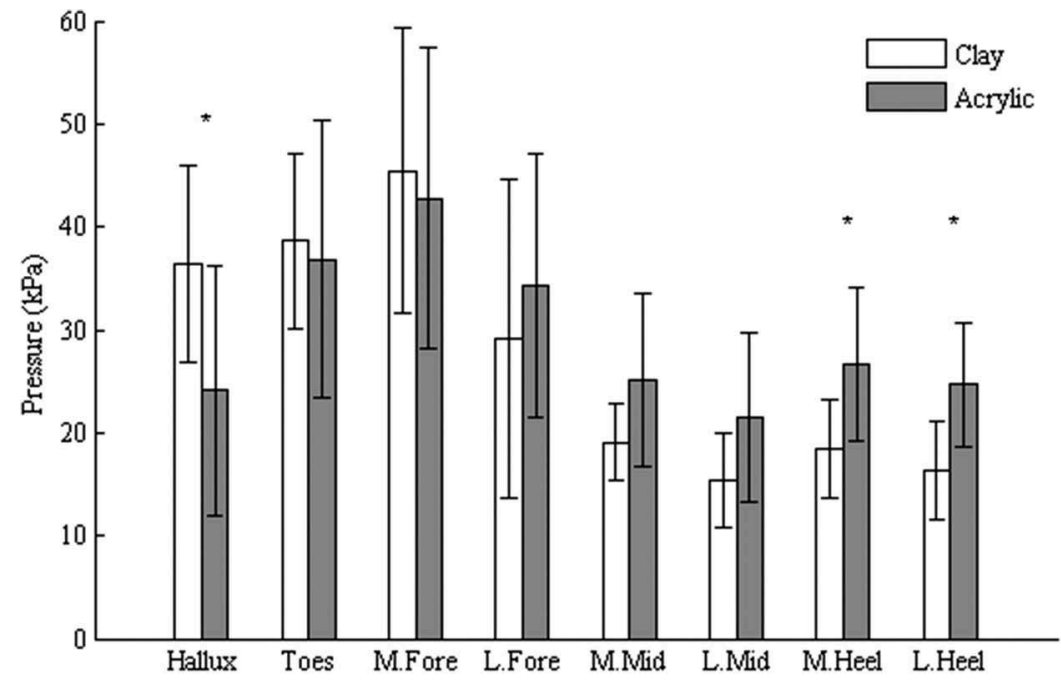

Figure 7. Mean pressures for the eight masks on acrylic and clay court.

${ }^{*}$ Denotes a $(P<0.05)$ difference between courts. 
only occurred in tennis players' biomechanical responses and perception of ability to turn on the surfaces.

\subsection{Player perceptions of tennis courts}

Players' perceptions of the courts inform their response to mechanical differences between surfaces (Milani et al., 1997), therefore measuring perceptions can provide an insight into how tennis players differentiate between court surfaces (Fleming et al., 2005). Similar to previous reports (Lockhart, Woldstad, Smith, \& Ramsey, 2002; Stiles \& Dixon, 2007), this study revealed differences in perception of the two tennis courts, which corresponded to differences in mechanical data. For instance, the acrylic court, which was mechanically harder and had greater friction, was perceived to be harder and resulted in greater perceptions of grip compared to the clay court. Unlike previous reports, this study examined additional perceptions such as perceived predictability and perceived ability to change direction and slide. Perceived predictability was lower on the low-friction surface which was also perceived to be easier to slide on yet difficult to change direction. These additional perception measures provided further information regarding player perception of tennis courts which could alter players' response to the surface, thus influencing injury risks and style of play. Results in this study suggest that the mechanical tests of hardness and friction that were used provided information regarding player perceptions of friction and hardness, yet other perceptions of the surface, such as predictability, were identified and should be considered during the future development of mechanical tests.

When developing mechanical tests and characterising tennis court surfaces, the collection of perceptions provides an indication of how players' respond to surfaces. Therefore, perceptions may reveal associations with biomechanical variables associated with increased injury risk. Measuring perception provides further information regarding players' experience of the surface which can not only supplement mechanical measures but also aid in the development of new mechanical tests (Fleming et al., 2005). This study identified differences in players' perceptions of their ability to perform tasks such as sliding and changing direction between court surfaces which could influence their biomechanical response. Therefore, it is recommended that future development of mechanical tests should attempt to replicate sliding and changing of direction type movements, with the use of biomechanical data such as applied loading characteristics and foot placements.

\subsection{Player response to tennis court differences}

Longer braking has previously been associated with high-friction surfaces and has been suggested to be an attempt to reduce high loading (Durá et al., 1999). In contrast, the current study reported longer braking on the low-friction clay court, observed through later peak active force and ankle dorsiflexion. These differences were attributed to longer contact times as a result of sliding on the court, unlike previous comparisons where sliding was not reported (Durá et al., 1999). The lower loading measured on the clay court compared with the acrylic is attributed to sliding on this court surface, and provides a suggested explanation for the lower injury incidences previously reported on lower friction tennis courts such as clay, in comparison to high-friction acrylic courts (Bastholt, 2000; Nigg \& Segesser, 1988).

Sliding in tennis can be beneficial by allowing braking to occur during stroke production thus allowing players to prepare for the next stroke immediately after ball strike making for a more efficient movement (Miller, 2006; Pavailler \& Horvais, 2015). As a result of sliding on clay, it was apparent that an altered turning technique (e.g. differences in initial knee flexion, attack angle, pressure distribution) occurred compared to the acrylic court where no sliding was observed, as hypothesised. This study revealed greater knee flexion at ground contact and reduced GRF on clay, both of which have been associated with improved stability on low-friction surfaces during walking (Heiden et al., 2006). Flexion at the knee has previously been suggested to improve stability through lowering the centre of mass (COM) closer to the base of support (Cham \& Redfern, 2002; Marigold \& Patla, 2002). High knee flexion during cutting movements has also been suggested to reduce risk of $A C L$ injuries on low-friction surfaces (Dowling et al., 2010). Thus, the more extended knee at initial ground contact on the acrylic court observed in the current study may increase risk of $A C L$ injuries when performing on this surface compared with low-friction clay.

Participants approach to the clay court was consistent with results previously reported from walking studies (Heiden et al., 2006). Greater attack angle on the clay suggests a more upright position at ground contact. A more upright attack angle has previously been associated with an anterior COM shift, suggested to improve stability (Clark \& Higham, 2011) in addition to lower COM through greater knee flexion. In contrast to the clay court, all players had a more aggressive approach through lower attack angle on the acrylic court. This aggressive approach observed on the acrylic court agrees with findings reported by Girard et al. (2007) and reflects the explosive playing style often observed on acrylic courts (O'Donoghue \& Ingram, 2001).

Unlike previous reports, where greater whole foot mean and maximum pressures on acrylic courts compared to clay courts have been reported (Damm et al., 2012; Girard et al., 2007), few differences were obtained between the acrylic and clay courts. Findings from this study were similar to those reported during walking where altered pressure distributions between surfaces accounted for a lack of whole foot pressure differences (Fong, Mao, Li, \& Hong, 2008). The greater pressures in the hallux area observed on the clay court compared to the acrylic court suggest increased grip needed to turn on the lower friction surface, which is similar to Fong et al. (2008) who suggested that greater toe grip and lower heel pressures provided balance and grip during walking on slippery surfaces. Players' ability to increase grip on the low-friction clay court through greater hallux pressures may increase risk of tendinopathy of the flexor hallucis longus, which develops during repetitive loading in the big toe area (Lynch \& Renström, 2002; Trepman, Mizel, \& Newberg, 1995). In agreement with Damm et al. (2014), greater lateral pressures at the 
heel, midfoot and forefoot were reported on the acrylic court suggesting a more inverted foot position which has previously been linked to increased risk of ankle inversion injuries (Kristianslund et al., 2011).

In contrast to Girard et al. (2007), the current study reported lower midfoot pressures on the clay court compared to the acrylic court. This response has been suggested to facilitate sliding on this type of surface by limiting areas of high pressure to prevent "sticking" (Damm et al., 2012). Girard et al. (2007) reported higher midfoot loading on clay compared with acrylic hardcourt, suggesting this permitted controlled sliding. Additionally, Girard et al. (2007) reported higher hallux pressures on acrylic attributed to a more aggressive play possibly as a result of greater friction. The findings reported in the current study differed to those reported by Girard et al. (2007), likely due to the different methods of analysing pressure data. Girard et al. (2007) examined the global effect of playing surface on pressure during two movements, serve and volley and baseline movements, therefore combining pressure distributions from multiple steps which consisted of accelerations, running and cutting which differ in pressure distribution patterns (Orendurff et al., 2008). Girard et al. (2007) collected data during whole tennis strategies (e.g. serve and volley) whilst this study specifically examined the turning step. Examining pressure distribution during individual steps rather than multiple steps allows more detailed understanding of the surface effects and the specific implications regarding injury risks.

\subsection{The influence of previous clay court experience on perceptions and biomechanical response}

Despite evidence that previous experiences combined with sensory information are used to formulate perceptions (Coren et al., 1979; Gescheider \& Bolanowski, 1991; Goldstein, 1999), when examining the influence of prior clay court experience on perceptions of tennis courts few differences were reported between experience groups. This lack of difference in surface perceptions was likely influenced by the familiarisation given to the participants prior to data collection, allowing them time to observe and gain some experience of the court. This was felt necessary for safety reasons, but may have limited the ability to detect differences between experience groups.

It was hypothesised that those with prior experience of clay courts would adapt to increase stability through reduced GRF and further increases in initial knee flexion compared to the low-experience group. However, findings from the current study failed to support this hypothesis. The lack of agreement with previous literature is most likely due to the nature of the population and the movement. Previous literature has focused on walking (Heiden et al., 2006), whilst the current study examined a more dynamic movement.

Prior experience on clay produced further adaptions such as altered initial ankle flexion and occurrence time of peak knee flexion which were not observed in the low-experience group. In particular, the experience group were in a plantar flexed position at ground contact on the clay yet slightly dorsiflexed on the acrylic; however, the low-experience group did not differ in initial ankle flexion angle between courts. Those with prior experience on clay had later peak knee flexion, suggesting that regular play on clay results in adaptations to reduce loading through longer braking phases (Durá et al., 1999), potentially reducing injury risk on certain tennis courts. These changes in response between the groups suggest that although participants perceived similarly, experience leads to additional biomechanical responses to surface manipulation.

\section{Limitations}

The use of on-court analysis in this study was a limitation regarding reproducibility of the tennis-specific movements. Yet, the benefits of an on-court analysis using the tennisspecific drills provided realistic conditions which are often difficult to obtain in confined laboratory conditions, thus improving the ecological validity. Even with the limitations regarding reliable reproduction of the movement between trials, statistical differences between surfaces were detected.

Low sampling frequency of kinematic $(50 \mathrm{~Hz})$ and pressure $(100 \mathrm{~Hz})$ data was a limiting factor which increases synchronisation error within the data and reduces accuracy of temporal data. In support of the data collected, values were similar to those reported in the literature. It is possible that the presence of the pressure insoles within the footwear influenced participants movement on the tennis court (Kong \& De Heer, 2009). However, it was felt that the data obtained through the use of these insoles were appropriate for obtaining on-court loading characteristics, and that the influence on footwear environment was small compared with the large differences in surface characteristics. The Pedar system used for pressure data collection (Pedar, Novel) has been suggested to be acceptably accurate and reliable (Godi, Turcato, Schieppati, \& Nardone, 2014; Price, Parker, \& Nester, 2014).

The anchor words employed in the visual analogue scale, previously deemed a reliable measure of perception (Mills, Blanch, \& Vicenzino, 2010; Mündermann, Nigg, Stefanyshyn, \& Humble, 2002), may be interpreted differently by different people (Aitken, 1969). However, previous pilot work supported that face validity of the questionnaire was achieved, thus minimising the ambiguity of the questionnaire (Starbuck, 2015).

\section{Conclusions}

Participants in this study were able to perceive differences between tennis courts and produced altered biomechanical responses as a result of different surface properties. As hypothesised, players perceived differences in perceived hardness and perceived grip between the tennis courts, in agreement with the mechanical data collected. Evidence suggests the inclusion of multiple perception measures such as perceived predictability and ability to perform tennis-specific tasks, to develop a more global approach to characterising tennis court surfaces. The use of perception and biomechanical data during on-court analysis could inform the development of mechanical tests to better replicate player experience. All participants in the current study demonstrated adaptations 
consistent with providing improved stability on the clay court during sliding, whilst those with greater experience on clay had additional adaptations such as later knee flexion, reducing rate of loading and potentially reducing injury risk. Previous experience does not appear to influence players' perceptions of tennis courts but provides information regarding an appropriate response. Although not directly measured due to a failed wireless transmission, later occurrence of peak knee flexion for the experienced group suggests lower GRF when compared to the low-experienced group, as hypothesised. This evidence suggests that when on clay, players with high previous experience are better able to accommodate to the court, through additional biomechanical responses, highlighting the importance of court familiarisation.

\section{Acknowledgements}

The authors would like to thank the International Tennis Federation and the Lawn Tennis association for their support during the study.

\section{Disclosure statement}

No potential conflict of interest was reported by the authors.

\section{References}

Abel-Aziz, Y., \& Karara, H. (1971). Direct linear transformation from comparator coordinates into object space coordinates (pp. 1-18). Urbana, IL: American Society of Photogrammetry.

Abrams, G. D., Renstrom, P. A., \& Safran, M. R. (2012). Epidemiology of musculoskeletal injury in the tennis player. British Journal of Sports Medicine, 46(7), 492-498. doi:10.1136/bjsports-2012-091164

Aitken, R. (1969). Measurement of feelings using visual analogue scales. Proceedings of the Royal Society of Medicine, 62(10), 989.

Bastholt, P. (2000). Professional tennis (ATP Tour) and number of medical treatments in relation to type of surface. Medicine and Science in Tennis, 5 (2). Retrieved from http://www.stms.nl

Brechue, W. F., Mayhew, J. L., \& Piper, F. C. (2005). Equipment and running surface alter sprint performance of college football players. The Journal of Strength \& Conditioning Research, 19(4), 821-825.

Carre, M., James, D., \& Haake, S. (2006). Hybrid method for assessing the performance of sports surfaces during ball impacts. Proceedings of the Institution of Mechanical Engineers, Part L: Journal of Materials: Design and Applications, 220(1), 31-39. doi:10.1243/14644207JMDA78

Cham, R., \& Redfern, M. S. (2002). Changes in gait when anticipating slippery floors. Gait \& Posture, 15(2), 159-171. doi:10.1016/S0966-6362 (01)00150-3

Chard, M. D., \& Lachmann, S. M. (1987). Racquet sports-patterns of injury presenting to a sports injury clinic. British Journal of Sports Medicine, 21 (4), 150-153. doi:10.1136/bjsm.21.4.150

Chiou, S.-Y., Bhattacharya, A., \& Succop, P. A. (2000). Evaluation of workers' perceived sense of slip and effect of prior knowledge of slipperiness during task performance on slippery surfaces. American Industrial Hygiene Association Journal, 61(4), 492-500. doi:10.1080/15298660008984560

Clark, A. J., \& Higham, T. E. (2011). Slipping, sliding and stability: Locomotor strategies for overcoming low-friction surfaces. The Journal of Experimental Biology, 214(8), 1369-1378. doi:10.1242/jeb.051136

Clarke, J., Carré, M. J., Damm, L., \& Dixon, S. (2013). The development of an apparatus to understand the traction developed at the shoe-surface interface in tennis. Proceedings of the Institution of Mechanical Engineers, Part P: Journal of Sports Engineering and Technology, 227(3), 149-160. doi:10.1177/1754337112469500
Cohen, J. (1977). Statistical power analysis for behavioral sciences (Revised ed.). London: Academic Press.

Coren, S., Porac, C., \& Ward, L. M. (1979). Sensation and perception. London: Academic Press.

Damm, L., Low, D., Richardson, A., Clarke, J., Carré, M., \& Dixon, S. (2013). The effects of surface traction characteristics on frictional demand and kinematics in tennis. Sports Biomechanics, 12, 389-402. doi:10.1080/ 14763141.2013.784799

Damm, L., Starbuck, C., Stocker, N., Clarke, J., Carré, M., \& Dixon, S. (2012, April 4). Plantar pressure depends on the playing surface in tennis. Paper presented at the BASES Biomechanics Interest Group, University of Ulster.

Damm, L., Starbuck, C., Stocker, N., Clarke, J., Carré, M., \& Dixon, S. (2014), Shoe-surface friction in tennis: Influence on plantar pressure and implications for injury. Footwear Science, 6, 155-164. doi:10.1080/ 19424280.2014.891659

Dixon, S. J., Collop, A. C., \& Batt, M. E. (2000). Surface effects on ground reaction forces and lower extremity kinematics in running. Medicine \& Science in Sports \& Exercise, 32, 1919-1926. doi:10.1097/00005768200011000-00016

Dowling, A. V., Corazza, S., Chaudhari, A., \& Andriacchi, T. (2010). Shoesurface friction influences movement strategies during a sidestep cutting task: Implications for anterior cruciate ligament injury risk. The American Journal of Sports Medicine, 38(3), 478-485. doi:10.1177/ 0363546509348374

Durá, J. V., Hoyos, J. V., Martínez, A., \& Lozano, L. (1999). The influence of friction on sports surfaces in turning movements. Sports Engineering, 2 (2), 97-102. doi:10.1046/j.1460-2687.1999.00024.x

Farley, C. T., Glasheen, J., \& McMahon, T. A. (1993). Running springs: Speed and animal size. The Journal of Experimental Biology, 185(1), 71-86.

Ferris, D. P., Liang, K., \& Farley, C. T. (1999). Runners adjust leg stiffness for their first step on a new running surface. Journal of Biomechanics, 32(8), 787-794. doi:10.1016/S0021-9290(99)00078-0

Fleming, P., Young, C., Roberts, J., Jones, R., \& Dixon, N. (2005). Human perceptions of artificial surfaces for field hockey. Sports Engineering, 8 (3), 121-136. doi:10.1007/BF02844013

Fong, D., Mao, D., Li, J., \& Hong, Y. (2008). Greater toe grip and gentler heel strike are the strategies to adapt to slippery surface. Journal of Biomechanics, 41(4), 838-844. doi:10.1016/j.jbiomech.2007.11.001

Gecha, S., \& Torg, E. (1988). Knee injuries in tennis. Clinics in Sports Medicine, 7(2), 435.

Gescheider, G. A., \& Bolanowski, S. J. (1991). Final comments on ratio scaling of psychological magnitudes. In G. A. Gescheider \& S. J. Bolanowski (Eds.), Ratio scaling of psychological magnitude: In honor of the memory of S. S. Stevens. Hillsdale, New Jersey: Lawerence Erlbaum Associates.

Girard, O., Eicher, F., Fourchet, F., Micallef, J. P., \& Millet, G. P. (2007). Effects of the playing surface on plantar pressures and potential injuries in tennis. British Journal of Sports Medicine, 41(11), 733-738. doi:10.1136/ bjsm.2007.036707

Girard, O., Micallef, J. P., \& Millet, G. P. (2010). Effects of the playing surface on plantar pressures during the first serve in tennis. International Journal of Sports Physiology \& Performance, 5(3), 384-393.

Godi, M., Turcato, A. M., Schieppati, M., \& Nardone, A. (2014). Test-retest reliability of an insole plantar pressure system to assess gait along linear and curved trajectories. Journal of Neuroengineering and Rehabilitation, 11(1), 3-11. doi:10.1186/1743-0003-11-95

Goldstein, B. (1999). Sensation and perception (5th ed.). London: Brooks/ Cole.

Grood, E. S., \& Suntay, W. J. (1983). A joint coordinate system for the clinical description of three-dimensional motions: Application to the knee. Journal of Biomechanical Engineering, 105, 136. doi:10.1115/1.3138397

Heiden, T. L., Sanderson, D. J., Inglis, J. T., \& Siegmund, G. P. (2006). Adaptations to normal human gait on potentially slippery surfaces: The effects of awareness and prior slip experience. Gait \& Posture, 24 (2), 237-246. doi:10.1016/j.gaitpost.2005.09.004

Hurkmans, H., Bussmann, J., Benda, E., Verhaar, J., \& Stam, H. (2006). Accuracy and repeatability of the Pedar Mobile system in long-term vertical force measurements. Gait \& Posture, 23(1), 118-125. doi:10.1016/j.gaitpost.2005.05.008 
Kong, P. W., \& De Heer, H. (2009). Wearing the F-Scan mobile in-shoe pressure measurement system alters gait characteristics during running. Gait \& Posture, 29(1), 143-145. doi:10.1016/j.gaitpost.2008.05.018

Kristianslund, E., Bahr, R., \& Krosshaug, T. (2011). Kinematics and kinetics of an accidental lateral ankle sprain. Journal of Biomechanics, 44(14), 2576-2578. doi:10.1016/j.jbiomech.2011.07.014

Lockhart, T. E., Woldstad, J. C., Smith, J. L., \& Ramsey, J. D. (2002). Effects of age related sensory degradation on perception of floor slipperiness and associated slip parameters. Safety Science, 40(7-8), 689-703. doi:10.1016/S0925-7535(01)00067-4

Lynch, S. A., \& Renström, P. (2002). Foot problems in tennis (pp. 155-164). Oxford: Blackwell.

Marigold, D. S., \& Patla, A. E. (2002). Strategies for dynamic stability during locomotion on a slippery surface: Effects of prior experience and knowledge. Journal of Neurophysiology, 88(1), 339-353.

Milani, T. L., Hennig, E. M., \& Lafortune, M. A. (1997). Perceptual and biomechanical variables for running in identical shoe constructions with varying midsole hardness. Clinical Biomechanics, 12(5), 294-300. doi:10.1016/S0268-0033(97)00008-9

Miller, S. (2006). Modern tennis rackets, balls, and surfaces. British Journal of Sports Medicine, 40(5), 401-405. doi:10.1136/bjsm.2005.023283

Miller, S., \& Capel-Davies, J. (2006, April 26). An initial ITF study on performance standards for tennis court surfaces. Paper presented at the SportSurf 2nd Workshop, Cranfield University.

Mills, K., Blanch, P., \& Vicenzino, B. (2010). Identifying clinically meaningful tools for measuring comfort perception of footwear. Medicine \& Science in Sports \& Exercise, 42(10), 1966-1971. doi:10.1249/MSS.0b013e $3181 \mathrm{dbacc} 8$

Mündermann, A., Nigg, B. M., Stefanyshyn, D. J., \& Humble, R. N. (2002) Development of a reliable method to assess footwear comfort during running. Gait \& Posture, 16(1), 38-45. doi:10.1016/S0966-6362(01)00197-7

Nigg, B. M., \& Segesser, B. (1988). The influence of playing surfaces on the load on the locomotor system and on football and tennis injuries. Sports Medicine, 5(6), 375-385. doi:10.2165/00007256-198805060-00003

O'Donoghue, P., \& Ingram, B. (2001). A notational analysis of elite tennis strategy. Journal of Sports Sciences, 19(2), 107-115. doi:10.1080/ 026404101300036299

Orendurff, M., Rohr, E. S., Segal, A. V., Medley, J. D., Green, J. R., \& Kadel, N. J. (2008). Regional foot pressure during running, cutting, jumping, and landing. The American Journal of Sports Medicine, 36(3), 566-571. doi:10.1177/0363546507309315

Pavailler, S., \& Horvais, N. (2015). Trunk and lower limbs muscular activity during tennis-specific movements: Effect of sliding on hard and clay court. Footwear Science, 7(sup1), S68-S70. doi:10.1080/ 19424280.2015.1038612

Price, C., Parker, D., \& Nester, C. J. (2014). Validity and repeatability of three commercially available in-shoe pressure measurement systems. Journal of Foot and Ankle Research, 7(Suppl 1), A67. doi:10.1186/1757-1146-7S1-A67

Reid, M. M., Duffield, R., Minett, G. M., Sibte, N., Murphy, A. P., \& Baker, J. (2013). Physiological, perceptual, and technical responses to on-court tennis training on hard and clay courts. The Journal of Strength \& Conditioning Research, 27(6), 1487-1495. doi:10.1519/ JSC.0b013e31826caedf

Sherwood, L. (1993). Human physiology: From cells to systems. St. Paul, MN: West Publishing Company.

Soutas-Little, R. W., Beavis, G. C., Verstraete, M. C., \& Markus, T. L. (1987). Analysis of foot motion during running using a joint co-ordinate system. Medicine \& Science in Sports \& Exercise, 19, 285-293. doi:10.1249/ 00005768-198706000-00016

Starbuck, C. (2015). Player perceptions and biomechanical responses to tennis court surfaces: The implications to technique and injury risk. Exeter: University of Exeter.

Stiles, V. H., \& Dixon, S. J. (2007). Biomechanical response to systematic changes in impact interface cushioning properties while performing a tennis-specific movement. Journal of Sports Sciences, 25(11), 1229-1239. doi:10.1080/02640410600983616

Trepman, E., Mizel, M. S., \& Newberg, A. H. (1995). Partial rupture of the flexor hallucis longus tendon in a tennis player: A case report. Foot \& Ankle International, 16(4), 227-231. doi:10.1177/107110079501600412

Willems, T. M., Witvrouw, E., Delbaere, K., Philippaerts, R., De Bourdeaudhuij, I., \& De Clercq, D. (2005). Intrinsic risk factors for inversion ankle sprains in females - a prospective study. Scandinavian Journal of Medicine \& Science in Sports, 15(5), 336-345. doi:10.1111/ sms.2005.15.issue-5

Yang, Z. (2010). Connecting tennis court surface characteristics to players' perception (Unpublished doctoral dissertation). The University of Sheffield, Sheffield. 